\title{
A validation of a cloud migration readiness assessment instrument: case studies
}

\author{
Abdulrahman A. Alshdadi ${ }^{1} \cdot$ Rayed AlGhamdi $^{2}$ - Madini O. Alassafi ${ }^{2} \cdot$ Ahmed S. Alfakeeh $^{3} \cdot$ Majid H. Alsulami $^{4}$
}

Received: 27 March 2020 / Accepted: 30 June 2020 / Published online: 13 July 2020

(c) Springer Nature Switzerland AG 2020

\begin{abstract}
Higher education institutions could introduce enormous cloud-based educational services that satisfy their stakeholders' IT needs. Migration to these pools of cloud services is multiple decision-making processes that are impacted by different organizational and technological obstacles and drivers. Investigating the preparedness of the internal technological and organizational capabilities of a university still lacks investigation particularly in Saudi Arabia. In this study, the practicality of a research instrument called Cloud Migration Readiness Assessment (CMRA) is assessed by using three case studies. The development of the instrument was published earlier. In this study, the validation of the instrument outputs is investigated by assessing the readiness of the three cases that already have planned to adopt the cloud computing services. Subsequently, the practicality and usefulness of the CMRA were assessed using a questionnaire and interviews with IT specialists in the three selected cases. The main contribution of this study is the validation and evaluation of the CMRA tool in real-world context using three different case studies in Saudi Universities.
\end{abstract}

Keywords Cloud migration · Readiness instrument · Saudi universities · Case studies · Validation study

\section{Introduction}

Migration to cloud-based services can provide educational institutions with various IT capabilities including increased efficiency, scalability, agility, high availability, and access to cutting edge IT services [1, 2]. Cloud paradigm is defined as "A type of parallel and distributed system consisting of a collection of interconnected and virtualized computers that are dynamically provisioned and presented as one or more unified computing resources based on service level agreements established through negotiation between the service provider and consumers" [3].

According to Educause survey [4], nearly most of the higher educational institutions have an interest in migrating to the cloud services. Most European and American countries have started to embrace the cloud by insisting and developing a cloud nation strategy to deliver IT solutions to their stakeholders. However, the Middle East and North African countries region (MENA) are slowly intending to adopt cloud-based educational services [5-7]. A big number of the population in Saudi Arabia is youth studying in public or private universities/colleges. Based on recent statistics, the number of Saudi citizens is $21.1 \mathrm{mil}-$ lion [8]. About a quarter of the Saudi population (24.1\%) are in the age range of 15-29 years. In 2020, the number of mobile subscriptions reaches 41.3 million, almost double the population number. It is 123.63 mobile phone subscriptions per 100 citizens. When it comes to the percentage of the population owning smartphones and having access to the Internet, it is $92 \%$ and $93 \%$, respectively. The

$\triangle$ Rayed AIGhamdi, raalghamdi8@kau.edu.sa| ${ }^{1}$ Department of Information Systems and Technology, College of Computer Science and Engineering, University of Jeddah, Jeddah, Saudi Arabia. ${ }^{2}$ Department of Information Technology, Faculty of Computing and Information Technology, King Abdulaziz University, Jeddah, Saudi Arabia. ${ }^{3}$ Department of Information System, Faculty of Computing and Information Technology, King Abdulaziz University, Jeddah, Saudi Arabia. ${ }^{4}$ College of Community, Shaqra University, Shaqra, Saudi Arabia. 
average usage time of the Internet is $7.46 \mathrm{~h}$. This poses importance to provide ICT resources that are capable to handle the demand of the students and the academics of ICT workload to enhance their teaching and learning experience $[9,10]$. Cloud-based resources can play a major role in enhancing the IT infrastructure as it can be scaled dynamically thereby supporting university stakeholders with flexible on-demand computing power, developing platforms, and ready software services.

The adoption of cloud computing provides immense benefits to higher educational institutes. One notable benefit of adopting such technology is the offered services by Microsoft and Google to educational institutes through cloud services. Higher educational institutes can save time and money investing in similar technologies that they develop and own themselves [11]. In general, the adoption of cloud computing offers greater flexibility, scalability, and mobility in the usages of technology resources for teaching and learning [12]. Having said that, some challenges may arise. These challenges may include security, privacy, and legal issues. One popular example of legal issues is the adoption of e-mail services by Google for wide global universities. It has been reported by a Canadian university, Lakehead University, that outscoring e-mail services to Google makes the university data disclosed to the USA government without their permission since Google is an American company. Therefore, the university revises its outsourced services [13].

It is believed by industry experts that the percentage of higher education institutes that adopt cloud computing services will increase significantly [4]. While these institutes moving forward to adopt such services, it is necessary to consider a careful evaluation of how and what kind of solution can be adopted [14].

The literature that investigated cloud computing adoption can be classified under two domains: adoption factors and adoption processes $[15,16]$. It has been suggested that the insightful investigation of the internal readiness for organizations to adopt cloud computing is an essential and critical step. Therefore, case studies that provide recommendations for best practices of an organization's preparation, selection of service model, and issues of contract negotiation are needed [15-17].

With the relatively recent existence of the cloud computing model, the transfer from traditional ICT to infrastructure that supports smooth adoption and use of cloud computing services can be critically challenging for developing countries including Saudi Arabia $[17,18]$. These challenges include factors related to culture, organizations, and infrastructures that might impede a successful information technology project deployment in Saudi organizations [19]. To facilitate IT projects and e-government services at a national level, the Saudi government has launched its e-government program called Yesser. Yesser has not yet accomplished the total objectives of smooth transmission to e-government services due to insufficient IT infrastructure, lack of public computing knowledge, shortage of qualified IT professionals, and lack of essential privacy and security systems $[5,19,20]$. The literature has a rich investigation of these issues concerning cloud computing in different contexts in the developed countries [21]. While these studies can be used to investigate the same situation at the national level in Saudi Arabia, the Saudi context substantially has different socio-cultural, political and government infrastructure. Therefore, empirical evidence from the local context is important to provide [20-22].

This research mainly aims to measure cloud migration readiness criteria that influence universities in Saudi Arabia to switch to the cloud paradigm. These technological and organizational measuring items in Cloud Migration Readiness Assessment (CMRA) are initially termed as Critical Success Factors (CSFs) and then were identified and adopted in CMRA instrument as metrics that are introduced in the previous study which were focused on developing and confirming the CMRA instrument [23]. Based on our previously reported results [23], a validation study in real-world settings is needed to validate and evaluate the developed CMRA instrument. The current phase of this study research was carried out in applying the CMRA instrument in three case studies to measure Saudi Universities' readiness in order to validate its content and evaluate its usefulness, satisfaction, and practicality. Therefore, the following research question is formulated: How good is CMRA's instrument practicality and functionality? To answer this question, validating CMRA instrument practicality and evaluating the CMRA instrument usefulness will be carried out.

\section{Related Studies}

Simply, cloud migration can be defined as a process of owning or outsourcing cloud-based networks' applications and services at partial or full of an organization level [3]. Cloud migration readiness at organizations is considered an active research area. Kauffman et al. [24] developed an evaluation metric of an organization's readiness for cloud computing migration. They identified four dimensions for this metric: organization and strategy, regulation and environment, technology and performance, and economics and evaluation. More emphasis on this metric was paid on the factors that influence the enterprise's readiness than providing in-depth empirical investigation [24]. Similarly, different readiness and maturity models were proposed to evaluate to what extent organizations 
are ready for cloud migration $[25,26]$. These models paid high emphasis on software companies for application migration aspects and not considering other aspects or factors at the same level [26]. In the cloud applications migration context, assessment metric for legacy cloud applications before the migration and a Cloud Readiness Method to evaluate an organization's services for the cloud were developed by Corradini et al. [27]. These methods, however, evaluate only the IT systems and not considering other factors related to human elements, legal issues, and organizational aspects. Strategically, the emphasis was on developing a framework that addresses challenges of cloud governance and IT management identification and the impact of data security [28]. These studies bring out restriction coverage of factors related to risks, costs, and economic implications. They were hardly addressing factors related to compliance, policy, or SLAs' requirements. In addition, some factors related to the technical side were ignored or not designed as measurements of readiness such as reliability, interoperability, and other securityassociated issues.

There is a notable public interest in cloud computing adoption in Saudi Arabia. This shifting, however, was carried out without a national context methodological approach. As a result, a hard effort is needed to adopt a methodological approach for cloud computing in the Saudi context [22]. It was predicted by the International Data Corporation (IDC) that the usage of cloud computing services would reach $57.7 \%$ of the annual growth rate of ICT in Saudi Arabia [29]. Two telecommunication companies that exist in Saudi Arabia that provide cloud services [30]. However, many challenges need to be taken care of. Examples of these challenges are ownership of data policies, and cloud computing strategies, and national regulations. In response to the deficiency of cloud computing regulations, the Saudi Commission of Communication and Information Technology (CITC) has announced the ICT regulations that include items related to the cloud computing services [31].

The growth in the UK and European universities regarding the use of cloud computing services is progressing faster compared to the universities in the Middle East. Universities in the Middle East region have started relatively late, and they are considered in an initial phase to offer education through cloud computing [21]. It was mentioned that one of the main challenges for higher education institutes in Saudi Arabia for e-learning is telecommunication infrastructure [32]. There are other challenges such as efficiency, availability, reliability, portability, flexibility advantages of cost, and security [22]. These factors were considered the most important factors that need to be considered when thinking of adopting cloud computing in higher education institutes. In addition, project management is classified as the most important success factor in cloud computing adoption [33].

A study was conducted by Mansour [34] using a case study on cloud adoption for IUG university in Palestine. The study identified several critical success factors to adopt cloud computing. Some interesting factors that were identified include a physical location, support by top management, compliance with the current systems, and security-related aspects. However, the case study was related to a single institute. Therefore, the result of the outcomes of that study needs further investigation. Alrashed and Alotaibi [35] reached a conclusion that the users' attitudes, perceptions, and intentions to adopt and use cloud computing are crucial in the Saudi Arabian environment. They have a higher significance than technology-related factors. Therefore, researchers should give similar weight to these aspects when investigating such an area in the Saudi environment [35]. Some researchers have investigated the process of migrating to the cloud in the Saudi context $[11,18,22,36]$. However, these researches lack empirical investigation regarding the migration to cloud computing CSFs. The current study, therefore, participates in closing that gap by providing empirical investigation in the mentioned area.

\section{Methodology}

This section describes the adopted method for current research. The current research relies on case studies. A case study is a research strategy and empirical method to investigate phenomena in a real world [37]. The case study design is similar to any type of empirical studies [38, 39]. It contributes to the progress of a flexible approach and may include a fairly large amount of iteration in its steps [40]. For example, when there is no enough available data, an additional collection of data can be carried out. The design of the case study should have an established and specific goal from the beginning to reach a satisfactory result [41].

\section{(A) CMRA evaluation case study steps}

In the current research, case studies are used to assess the practicality of the developed CMRA instrument in three real-world cases. The design and procedures of the three selected cases are described as follows. It contains four steps: the selection of participants, readiness assessment, data collection and analysis, and practicality judgment of the proposed CMRA instrument.

The first step involved the participant selection. The participants were selected from three Saudi universities. To keep the identity confidential, the actual names are coded as Uni-A, Uni-B, and Uni-C. The selected participants 
from these three universities were IT specialists and seniors working in the relevant departments/deanships in the selected universities. The IT seniors, i.e. deans, VPs and HoDepts, were classified as group B whereas the IT specialists were classified as group A. The participants of group A were pooled from respective IT backgrounds and expertise with working experience minimum of two years at the same selected university. This process contributes to collect accurate data. Table 1 below describes the demographic profile of all the participants.

The second step involved assessing the cloud migration readiness of the three cases. Focus groups were organized from the selected IT specialists. The information sheet was handed to the participants, and they were asked to sign the participant consent form. Afterward, the CMRA questionnaire was provided to the participants using an online form. The readiness assessment was obtained using an online questionnaire. The questionnaire was constructed based on the Expectation Confirmation Model (ECM). The ECM assists in evaluating three variables: perceived usefulness and satisfaction and confirmation [42]. The questionnaire contained criteria of readiness. Four rating scales were used to evaluate each measurement item. The scale was adopted from the PAM model [43] and slightly changes based on the focus group interviews. The original PAM metrics use six levels: non-existent, initial, repeatable, defined, managed, and optimized. In the current research, five levels are used; run from 0 to 4 as follows: $0 \%$ for the non-existent process, $25 \%$ for initial process, $50 \%$ for the performed process, $75 \%$ for the managed process, and $100 \%$ for the optimized process.

Table 1 Participants demographic profile

\begin{tabular}{llrl}
\hline Info & Variable & Frequency $(N)$ & Percentage (\%) \\
\hline Gender & Male & 17 & 100 \\
Age & $28-35$ & 5 & 29.41 \\
& $36-45$ & 10 & 58.82 \\
University & $46-55$ & 2 & 11.76 \\
& Uni-A & 6 & 35.29 \\
Education level & Uni-B & 5 & 29.41 \\
& Uni-C & 6 & 35.29 \\
& Diploma & 1 & 5.88 \\
& Bachelor & 8 & 47.06 \\
Job role & Master & 3 & 17.65 \\
& PhD & 5 & 29.41 \\
& IT specialist & 12 & 70.59 \\
Years of exper- & Head of dep & 3 & 17.65 \\
tise & Dean/vice dean & 2 & 11.76 \\
& 2-5 years & 2 & 11.76 \\
& 6-10 years & 9 & 52.94 \\
\hline & 10+years & 6 & 35.29 \\
\hline
\end{tabular}

SN Applied Sciences

a SPRINGER NATURE journal
In the third step, the collected data were analyzed using a descriptive-analytical method. The results were presented on a chart scoring for the six readiness criteria for every case.

The fourth step involved the evaluation of the CMRA practicality. The IT specialists who used the CMRA to measure their university's readiness were requested to fill out the questionnaire. This is followed by interviewing five to six seniors in each university. The interviews were made to seek the seniors' perceptions regarding their universities' cloud migration readiness. Their opinions were obtained two times. The first time was before getting the results of their university readiness using our developed CMRA and the second time after presenting the results to them. After presenting the report results, they were requested to provide feedback on the accuracy of these results to their universities' actual practices.

\section{(B) Case studies' procedures}

An online questionnaire was developed to measure cloud migration readiness. It was hosted by the University of Southampton using iSurvey tools. The questionnaire constituted seven sections. The main parts contained the measurement items of the CMRA to assess the readiness status. During the sessions of assessments, participants of group A were interviewed to seek a view on the level of readiness for their universities. The researchers recorded the interview sessions. This process is called an interview-administrated questionnaire [44].

For the focus group, a semi-structured session was considered. A session of a semi-structured group is managed by a leader to gather information on an identified topic. A focus group facilitates interaction to generate data. This technique is believed practical as it helps to develop and validate instruments. The interviewing focus group was selected for the current study. Thus, the type of interviewing enriches the conversation with different types of views from different perspectives and experiences. It makes worthy exchanging and challenging different views at the same session making the conversation more mature [45-47].

The sample size, in the current study, for the focus group ranged from four to six per each group. In each university, one focus group was formed. The participating members of these groups were from different IT backgrounds. Upon the completion of each interview session, participants were requested to prioritize and rank the items of CMRA. The data of each case study were collected and statistically analyzed separately. Each assessment result of a readiness criterion was demonstrated to the participants in the form of a radar chart. 
After finalizing each case's report, it was handed to both groups $A$ and $B$ for each case. This was to seek their feedback on the CMRA practicality and accuracy. This step addresses the research question: "How good is CMRA's instrument practicality and functionality?".

\section{Results and Discussions}

In this section, the experimental results for each case that demonstrate the Readiness Criteria (RCs) in CMRA instrument which measures the readiness status for cloud migration projects are discussed. They were conducted to evaluate CMRA's instrument usefulness and validate its practicality and applicability. The presented data are used to demonstrate the related readiness scores to each case.

\subsection{CMRA assessment and result}

The CMRA final version is demonstrated in Table 2. Evaluation of CMRA's practicality and functionality was the aim of adopting the case studies. The CMRA instrument has two domains: technological and organizational domains. The technological part consists of three RCs: Reliability, Security, and Interoperability. The organizational domain consists of SLA requirements, migration plans, and regulations compliance. The total PQs in CMRA are 44, the technological domain has 25 measuring items that belong to the measuring processes (PQs) and the organizational domain has 19 measuring items that belong to the PQs.

\subsubsection{University-A findings and discussion}

This case represents a public university with about 25,000 students, faculty members, and employees. The university was established in 2014. It is considered a starting-up

Table 2 The CMRA's criteria final version

\begin{tabular}{|c|c|c|}
\hline \multicolumn{3}{|l|}{ Technological area } \\
\hline Readiness criteria (RCs) & Measuring processes (PQs) & Aggregation \\
\hline Reliability (RE) & $\begin{array}{l}\text { Disaster recovery (DR) } \\
\text { Data latency (DL) } \\
\text { Availability (AV) } \\
\text { Bandwidth (BW) }\end{array}$ & $\begin{array}{l}S_{T}=\sum_{i=1}^{n}\left(\frac{\sum_{j=1}^{m} p_{i j}}{m} * w_{i j}^{\mathrm{AHP}}\right) \\
\text { Where } S_{T} \text { is the final domain score, } n=3 \text { is } \\
\text { the number of } \mathrm{RCs}, m \text { is the number of Ps }\end{array}$ \\
\hline Security (SE) & $\begin{array}{l}\text { Security awareness and practice (SA) } \\
\text { Malicious detection (MD) } \\
\text { Security auditing (SD) } \\
\text { Physical security (PS) } \\
\text { Non-repudiation (NR) } \\
\text { Confidentiality (CF) } \\
\text { Integrity (INT) } \\
\text { Privacy (PV) }\end{array}$ & $\begin{array}{l}\text { for each RC and } w_{i j}^{\mathrm{AHP}} \text { is the AHP weight } \\
\text { calculated for each RC }\end{array}$ \\
\hline Interoperability (IN) & $\begin{array}{l}\text { Interoperability awareness and practices (IP) } \\
\text { Extensibility (EX) } \\
\text { Portability (PT) }\end{array}$ & \\
\hline \multicolumn{3}{|l|}{ Organizational area } \\
\hline SLA requirements (SLA) & $\begin{array}{l}\text { Service level requirements }(S L) \\
\text { Arabic language support }(A L) \\
\text { Technical support level (TS) } \\
\text { Security requirements (SR) } \\
\text { Cost requirements (CR) } \\
\text { Penalties (PN) }\end{array}$ & $\begin{array}{l}S_{O}=\sum_{i=1}^{n}\left(\frac{\sum_{j=1}^{m} p_{i j}}{m} * w_{i j}^{\mathrm{AHP}}\right) \\
\text { Where } S_{O} \text { is the final domain score, } n=3 \text { is } \\
\text { the number of RC, } m \text { is the number of Ps for } \\
\text { each RC and } w_{i j}^{\mathrm{AHP}} \text { is the AHP weight calcu- } \\
\text { lated for each RC }\end{array}$ \\
\hline Migration plan (MP) & $\begin{array}{l}\text { Performance assessment (PA) } \\
\text { Management support (MS) } \\
\text { Knowledge-base (KB) } \\
\text { IT staff training (ST) }\end{array}$ & \\
\hline Compliance with regulations (CR) & $\begin{array}{l}\text { Adherence to local regulations (LR) } \\
\text { Degree of data control (DC) } \\
\text { Data usage policies (DP) }\end{array}$ & \\
\hline
\end{tabular}


university as per the classification of the Saudi higher education system.

Recently, the university has started a cloud migration project with national telecommunication, Saudi Telecom Company (STC), and the project is still in its early stages. The main reason for selecting this case because of the confirmations received by its participants affirming they are planning to adopt the cloud computing system within a year.

The participants were requested to weight and prioritise the importance of each readiness criterion in the CMRA instrument according to their university best practices. Figure 1 demonstrates a chart scoring for the six readiness criteria. The security item was scored $52 \%$, the highest-scoring among all the other RCs. This is classified in a good area; however, there is room for improvement to be shifted to the upper level. The rest of the readiness criteria were classified in the adequate area capturing $45 \%, 40 \%, 38 \%, 29 \%, 29 \%$, respectively, for the reliability, compliance with regulations, SLA requirements, interoperability, and migration planning. This suggests that the area is at an average scale and considerable improvement to enable an appropriate cloud migration is needed.

The processes of the current case are classified as follows. Two processes were classified under the optimized maturity level. These processes are managing the "Access list" and "Up-time for the IT services". The Up-time for the IT Service for Uni-A scored a hundred percent (100\%). This further elaborated by the comments of the respondents. They indicate the use of specialized monitoring services such as HP OpenView for monitoring the infrastructure of information technology networks. Elven (11) processes

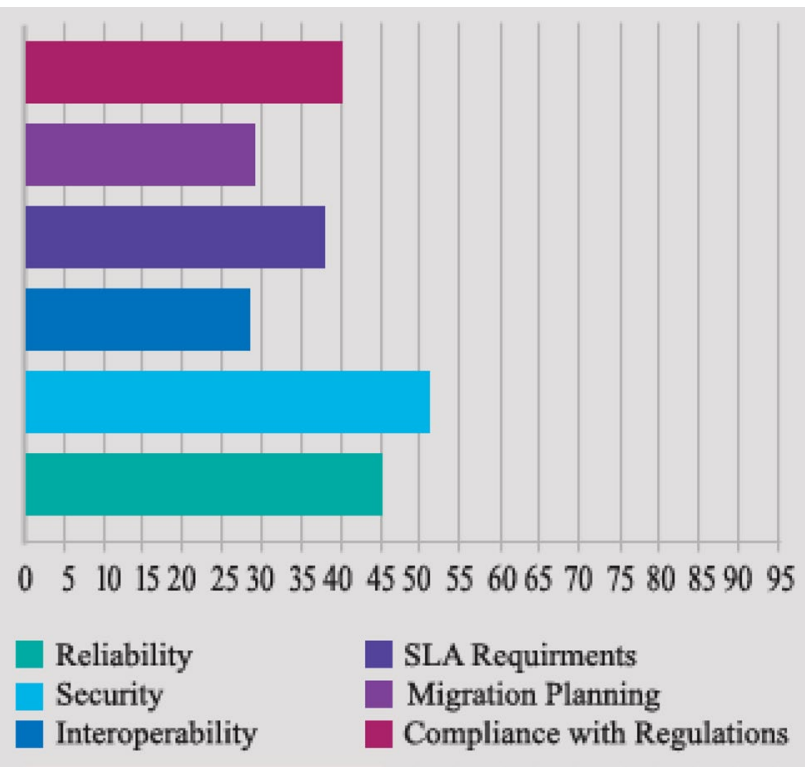

Fig. 1 Analysis of University-A for the six readiness criteria were classified under the defined maturity level, scored $50 \%$. Furthermore, 14 processes were classified under the initial maturity level, scored $25 \%$. Most readiness criteria statuses, in this case, are either in good or adequate areas. Hence, the overall score for the current case is $41 \%$.

\subsubsection{University-B findings and discussion}

This case study represents a public university with about 75,000 students, faculty members, and employees. The university was established in 2009. Similar to the first case, it is classified as starting-up as per the Saudi higher education system which classifies each university under the age of 10 years as a starting-up university.

This university was approached by the Microsoft cloud team in Riyadh to adopt its cloud beta project. At the time of conducting this research, they were studying this offer by Microsoft. Therefore, the main reason for selecting this case was their intention to adopt cloud computing services.

As per the process followed by the first case, the participants in the current case were asked to weigh and priorities the readiness criteria importance. Figure 2 illustrates a chart scoring for the six readiness criteria of University-B. The RCs in this university were classified into three areas: excellent, good, and adequate. Security was in an excellent area capturing a percentage of $79 \%$. This suggests that the area needs no further improvements. The process area is managed quite well, and no action is needed in this regard. Secondly, the reliability scored $70 \%$, in a good area. The other items were in the adequate area. These items were SLA requirements, Interoperability, Migration Planning,

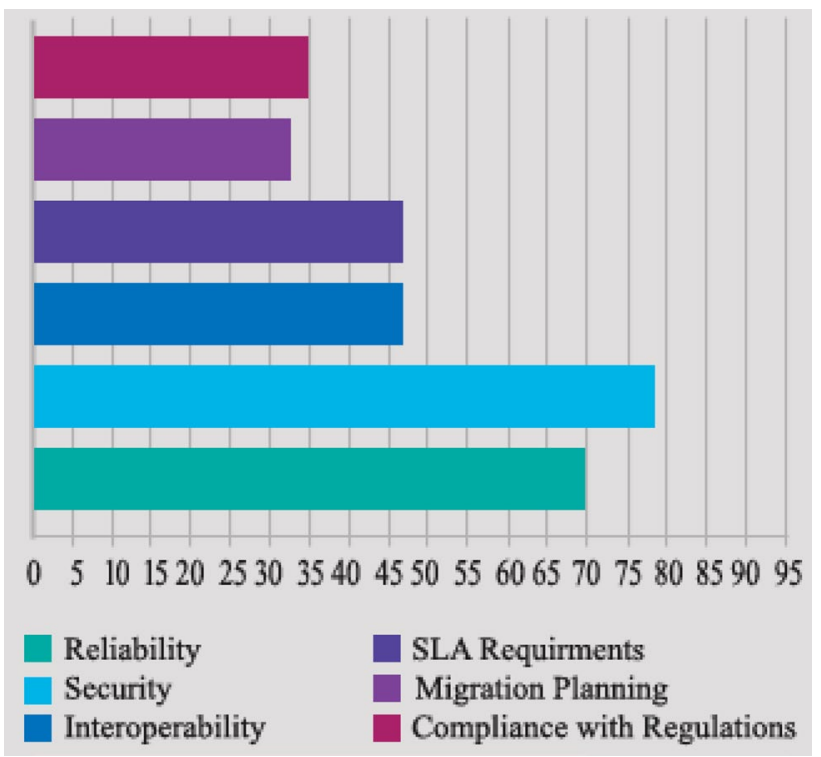

Fig. 2 Analysis of University-B for the six readiness criteria 
and compliance with regulations. They were scored $47 \%$, $46 \%, 33 \%$, and $30 \%$ respectively. The area is on an average scale, and considerable improvement is needed for enabling an appropriate process for cloud migration.

The processes, in this case, are classified as follows. Twelve processes were classified under the optimized maturity level. These processes are headed by documentation of technical support requirements and authentication capability. The authentication capability scored $100 \%$. This was further justified by the comments of the respondents that the authentication mechanism followed in this case is linked directly to every stakeholder's national security number. This national security number is generated by the Saudi government based on the national ID number. Furthermore, technical support requirements documentation scored $100 \%$. The participants indicated that encountering numerous issues for technical support made them experienced in managing their requirements. Secondly, in the managed maturity level, five processes were indicated. These processes were headed under physical security techniques, provision of recovery techniques, and the existence of a cloud RFP document. Overall, the readiness criteria status of the current case is either in excellent, good, or adequate areas. Hence, the overall readiness status score in this case is $62.7 \%$.

\subsubsection{University-C findings and discussion}

This case represents a public university with about 41,000 students, faculty members, and employees. The university was found in 2011. The university has invited three different telecommunication companies to submit their offers for cloud computing services. This case was selected because the decision was undertaken to adopt cloud computing.

Similarly, as conducted per the previous two cases, the participants, in this case, were asked to weigh and priorities the importance readiness criteria. Figure $3 \mathrm{dem}$ onstrates a chart scoring for the six readiness criteria of University-C. The RCs, in this case, were classified into three areas: good, adequate, and inappropriate. Security was scored $54 \%$, classifying it in a good area. The four RCs were scored 39\% for interoperability, 35\% for reliability, $34 \%$ for SLA requirements, and 33\% for migration planning. Whereas the remaining one RC namely compliance with regulations was the lowest score $(20 \%)$, in an inappropriate area. For items in an inappropriate area, major issues and weaknesses are existing. Thus, before deciding on migrating to the cloud, serious consideration and revision are crucial.

The processes, in this case, is classified as follows. First, one single process was classified under the optimized maturity level. It is the evaluation of physical protection. It

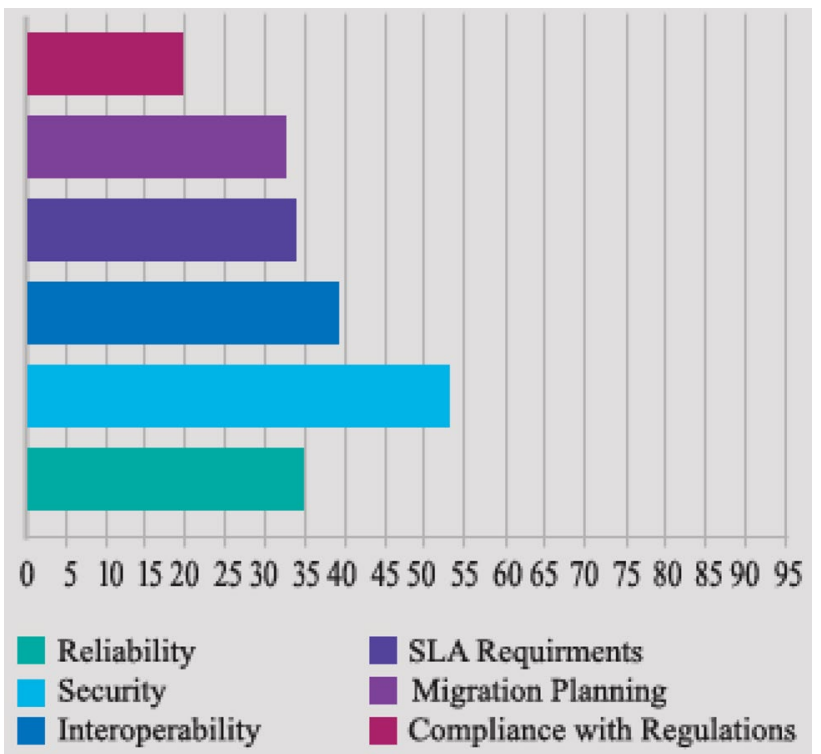

Fig. 3 Analysis of University-C for the six readiness criteria

was further justified by comments of the respondents that they have certain requirements and routine inspections to keep the data centre safe. Secondly in the managed maturity level, there were ten processes. These processes were listed under three groups: defining impact metrics, access lists, and identifying high up-time. For identifying high up-time, the following items were reported: $24 / 7$ services and immediate dealing with any interruption. For the access lists, the following item was reported: ongoing efforts for improvements and adhering to best practices. For the defining impact metrics, it was indicated that a dedicated department monitoring, rating the providers of information technology services, and setting up timely manner meetings to fix any raised issues while avoiding the lower performance of the organization. More ahead, in the defined maturity level, nine processes were listed. These processes were headed under malicious activities detection. Finally, in the initial maturity level, seventeen processes were listed.

Overall, the readiness criteria status of the Uni- $\mathrm{C}$ case is either in good, adequate, or inappropriate areas. Hence, the overall readiness status score in this case is $39.45 \%$.

\subsection{The CMRA practicality}

In this section, the CMRA usefulness and practicality are investigated. To reach this goal, the evaluation stage took place for both participants: the IT specialists and the senior managers in these three universities. First, twelve participants from different IT areas, working in the three universities, joined focus groups to assess the CMRA practicality using a questionnaire. In the questionnaire, ECM 
constructs, usefulness, satisfaction, and the similarities between uses expectation and its actual performance were adopted and customized to assess the CMRA. Afterward, in every case, five IT departments were invited as senior members to review the generated results from the focus group readiness assessment.

At first, the five members in every case were interviewed using semi-structured questions. They were asked about their organization's ongoing procedures and readiness to cloud migration. Then they were handed the focused group reports. Under each item of every case's report, they were asked:"Do you believe this score reflects your true readiness level to undertake the cloud migration in your university?". In the end, they were asked to answer the following question: "To what extent do you believe this instrument is useful in measuring weaknesses as well as strengths of the cloud migration processes' readiness in the Saudi universities' context?" They were provided with five possible answers to opt from, ranged from strongly agree, scored 5 , to strongly disagree, scored 1.

\subsubsection{CMRA reliability}

A questionnaire was handed manually and returned by all the 12 participated members. No concerns were reported with regard to the questions. Cronbach's alpha test was used to determine the status of reliability per each item that belongs to the three ECM's constructs. This process is further used for examining the measuring items' internal consistency [48]. Table 3 demonstrates that Cronbach's alpha values for each construct range from 0.71 to 0.818 , which exceeds the threshold of 0.7 , stating that the measuring items of each construct are reliable

\subsubsection{Analyzing questionnaire data}

The participated members who used the CMRA to evaluate the readiness of their university also participated in this evaluation questionnaire. The data were prepared for analysis using the SPSS V.23. Table 4 demonstrates the results of the one-sample $t$ test. The $t$ test was performed to test the difference of the mean rating of each question from the hypnotized rating value of three. The three rating value states "neither agree nor disagree" on the 5-points Likert scale adopted in this study questionnaire.

Table 4 indicates the agreement of the participants on CMRA's practicality and usefulness. The result indicates that each construct's mean value is bigger than the hypothesized test value of 3 . Besides, all the evaluation measuring items were held substantial. The P-values for all the measurement items are below 0.05 , which confirms that the responses were notably positive for the CMRA usefulness and practicality.

Table 5 demonstrates different perception levels of the three cases for the CMRA continuance intention. A

Table 4 One sample $t$ test's statistics for the constructs' items

\begin{tabular}{lcccl}
\hline Evaluation variables & $N$ & Sig. (2-tailed) & Mean & Std. deviation \\
\hline Q1-Usefulness & 12 & $<0.0001$ & 4.08 & 0.669 \\
Q2-Usefulness & 12 & $<0.0001$ & 4.58 & 0.515 \\
Q3-Usefulness & 12 & $<0.0001$ & 4.17 & 0.718 \\
Q4-Usefulness & 12 & 0.002 & 4.00 & 0.853 \\
Q1-Satisfaction & 12 & 0.043 & 3.75 & 1.138 \\
Q2-Satisfaction & 12 & 0.002 & 4.00 & 0.853 \\
Q3-Satisfaction & 12 & $<0.0001$ & 4.08 & 0.669 \\
Q1-Confirmation & 12 & 0.002 & 4.08 & 0.900 \\
Q2-Confirmation & 12 & $<0.0001$ & 4.25 & 0.754 \\
Q3-Confirmation & 12 & $<0.0001$ & 4.00 & 0.739 \\
\hline
\end{tabular}

Table 3 Cronbach's alpha value for each construct

\begin{tabular}{lll}
\hline Construct name & Total items & $\begin{array}{l}\text { Statements of measurement items } \\
\text { Perceived usefulness } 4\end{array}$ \\
& $\begin{array}{l}\text { This tool helps to assess the cloud migration readiness for my organization } \\
\text { This tool increases my awareness of the areas that need further consideration before migrating } \\
\text { to the cloud } \\
\text { This tool enhances my effectiveness in managing and accessing my organization's readiness for } \\
\text { migrating to the cloud } \\
\text { Overall, this tool is useful in assessing and assuring my organization's readiness level for migrat- } \\
\text { ing to the cloud } \\
\text { I am satisfied with the results of my organization's readiness using this tool } \\
\text { I am satisfied with the experience of using this tool } \\
\text { Overall, how would you rate your satisfaction with this tool? } \\
\text { My experience with using this tool is better than what l expected } \\
\text { The service level provided by this tool is better than what I expected } \\
\text { Overall, most of my expectations from using this tool are confirmed }\end{array}$ \\
& 3 & 0.729
\end{tabular}


Table 5 The CMRA three scaling items' mean for the three universities

\begin{tabular}{lllll}
\hline CMRA evaluation & & & & \\
\hline Item & $A$ & $B$ & $C$ & $\begin{array}{l}\text { Average } \\
\text { mean } \\
\text { score }\end{array}$ \\
\hline Usefulness & 3.5 & 4.56 & 4.35 & 4.21 \\
Satisfaction & 3.66 & 4.08 & 4 & 3.94 \\
Confirmation & 3.88 & 4.33 & 4.06 & 4.11 \\
\hline
\end{tabular}

similar level of CMRA usefulness was perceived by Uni-B and Uni-C (4.56, and 4.35, respectively), whereas Uni-A had a relatively lower scoring (3.5). Furthermore, construct scores for Uni-B and Uni-C were always within 4-5, whereas the case with Uni-A scores always lagged and stayed within the range of 3.5 and 3.9.

4.2.2.1 Perceived usefulness Table 6 presents high scoring, 3.88 and above, for the perceived usefulness construct. This indicates that there was an agreement of the CMRA usefulness for the three cases. The participated members highlighted that the current CMRA instrument would raise their universities' awareness, check the level of readiness, enhance effectiveness for managing, and measure the status of readiness. Generally, the perceived usefulness of the CMRA for assuring and assessing their university's readiness for cloud migration purposes is confirmed.

4.2.2.2 Satisfaction Table 7 demonstrates the satisfaction construct scoring as perceived by the participants, the three IT teams, in the three universities. There was an overall agreement about the experience of using the tools. The scoring for two items is 4 and above, and for one item is 3.43 , which still in a reasonable range. This scoring suggests that the current CMRA instrument satisfies the need to measure the readiness of an organization to move forward towards cloud computing services migration. The IT teams in the selected three cases were satisfied with the readiness status that was generated by this tool.
Table 7 Satisfaction construct scoring as perceived by the participants

\begin{tabular}{ll}
\hline Item & Score \\
\hline Q3-Overall, how would you rate your satisfaction with this & 4 \\
tool? & \\
Q2-I am confident with the experience of using this tool & 4.07 \\
Q1-I am satisfied with our organization readiness results & 3.43 \\
after using this tool & \\
\hline
\end{tabular}

4.2.2.3 Confirmation Table 8 shows the analogy perception between the CMRA usage expectation and its performance. The scale presents that most of the participants' expectations with this tool were confirmed. The result indicates that the service level of CMRA and the IT participants' experience was more than expected. The scoring for the confirmation construct is 3.94 and above for all the three listed items. This result suggests that the current CMRA instrument is confirmed by the three selected cases to meet their expectations.

\subsubsection{CMRA practicality feedback}

As discussed earlier, five senior members in each of the three universities were requested to provide feedback on the CMRA practicality. They were asked to provide answers on the appositeness of the CMRA for measuring the cloud migration readiness for their universities. Their feedback was looked for in two steps. First, they were interviewed in order to investigate the adopted processes and level of confidence about the current readiness status of their universities. Then, readiness reports of their respective universities were presented to them. They were requested to clarify their thoughts on to what extent the presented results reflect the actual readiness status of their respective universities.

Table 9 demonstrates the seniors' feedback. The responses of the three universities per each item were listed in three columns. The last column shows the average scoring for the tree causes. The scoring was calculated based on the responses as follows: 5 for SA (strongly agree), 4 for $\mathrm{A}$ (agree), 3 for $\mathrm{N}$ (neutral), 2 for $\mathrm{D}$ (disagree), and 1 for SD (strongly disagree).

Table 6 Perceived usefulness construct scoring as perceived by the participants

\begin{tabular}{ll}
\hline Item & Score \\
\hline Q3-Overall, this tool is useful in assessing and assuring my organization's readiness level for migrating to the cloud. \\
Q3-Using this tool enhances my effectiveness in managing and assessing the cloud migration readiness status of our organization & 4.09 \\
Q2-Using this tool increase my awareness about the areas that need further consideration before migrating to the cloud. & 4.56 \\
Q1-Using this tool helps assess the readiness status of my organization got cloud migration & 4.01
\end{tabular}


Table 8 Confirmation construct scoring as perceived by the participants

\begin{tabular}{ll}
\hline Item & Score \\
\hline Q3-Overall, most of my expectations from using this tool are confirmed & 3.94 \\
Q2-The service level provided by this tool is better than what I expected. & 4.24 \\
Q1-My experience with using this tool is better than what l expected & 4.10
\end{tabular}

\begin{tabular}{lllll}
\hline Feedback question & Uni-A & Uni-B & Uni-C & Feedback result \\
\hline Q1: Reliability (RE) & A & A & A & 4.00 \\
Q2: Security (SE) & SA & A & D & 3.66 \\
Q3: Interoperability (IN) & A & A & SA & 4.33 \\
Q4: SLA requirement (SL) & SA & SA & A & 4.66 \\
Q5: Migration plan (MP) & A & SA & SA & 4.66 \\
Q6: Compliance with regulations (CR) & SA & SA & SA & 5.00 \\
Q7: Overall readiness level & A & SA & SA & 4.66 \\
Q8: CMRA usefulness & SA & SA & A & 4.66 \\
\hline
\end{tabular}

SA strongly agree, $A$ agree
Table 9 CMRA practicality feedback six readiness criteria namely: security, interoperability, reliability, SLA requirements, migration planning, and compliance with a regulation, before and after deciding to cloud migration. By taking this step of the assessment, the failure and risks associated with deciding to migrate to cloud computing are minimized. It widens decisionmakers' understanding of the whole situation of their organizations before they move forward and plan well for every step they take.

\section{Compliance with ethical standards}

Conflict of interest On behalf of all authors, the corresponding author states that there is no conflict of interest.

\section{References}

1. Sultan N (2010) Cloud computing for education: a new dawn? Int J Inf Manage 30(2):109-116. https://doi.org/10.1016/j.ijinf omgt.2009.09.004

2. Alharthi A, Yahya F, Walters RJ, Wills G (2015) An overview of cloud services adoption challenges in higher education institutions. Emerging Software as a Service and Analytics 2015 Workshop (ESaaSA 2015), in conjunction with CLOSER 2015. 20-22 May 2015. pp 102-109

3. Buyya R, Yeo CS, Venugopal S (2008) Market-oriented cloud computing: vision, hype, and reality for delivering IT services as computing utilities. In: 2008 10th IEEE international conference on high performance computing and communications. IEEE, pp 5-13. https://doi.org/10.1109/hpcc.2008.172

4. Wheeler B, Waggener S (2009) Above-campus services: shaping the promise of cloud computing for higher education. Educ Rev 44(2009):10-22 
5. Alshwaier A (2012) A new trend for E-learning in KSA using educational clouds. Adv Comput Int J 3(1):81-97. https://doi. org/10.5121/acij.2012.3107

6. Alghamdi RA (2012) Diffusion of adoption of online retailing in Saudi Arabia. Ph.D. thesis, Griffith University, Brisbane

7. Alassafi MO, AlGhamdi R, Alshdadi A, Al Abdulwahid A, Bakhsh ST (2019) Determining factors pertaining to cloud security adoption framework in government organizations: an exploratory study. IEEE Access 7:136822-136835

8. TDC-Trend Digital Communication (2020) Saudi digitalization. Retrieved 4 June 2020, from http://trenddc.com/ar/blog/Saudi -Digitalization-2020-04-03-2020_1583338785

9. Alkhalaf S, Drew S, Alghamdi R, Alfarraj O (2012) E-learning system on higher education institutions in KSA: attitudes and perceptions of faculty members. Proc Soc Behav Sci 47:1199-1205

10. AIGhamdi R, Bahadad A (2018) Assessing the usages of LMS at KAU and proposing FORCE strategy for the diffusion. arXiv preprint arXiv: 1902.00953

11. Tashkandi AN, Al-Jabri IM (2015) Cloud computing adoption by higher education institutions in Saudi Arabia: an exploratory study. Cluster Comput 18(4):1527-1537

12. Ali MB, Wood-Harper T, Mohamad M (2018) Benefits and challenges of cloud computing adoption and usage in higher education: a systematic literature review. IJEIS 14(4):64-77

13. Okai $S$ et al (2014) Cloud computing adoption model for universities to increase ICT proficiency. SAGE Open 4(3):1-10. https://doi.org/10.1177/2158244014546461

14. Cisco I (2012) Cisco visual networking index: forecast and methodology, 2011-2016. CISCO White paper, 518

15. El-Gazzar RF (2014) A literature review on cloud computing adoption issues in enterprises. In: International working conference on transfer and diffusion of IT. Springer, Berlin, pp 214-242

16. Alassafi MO, Atlam HF, Alshdadi AA, Alzahrani Al, AlGhamdi RA, Buhari SM (2019) A validation of security determinants model for cloud adoption in Saudi organisations' context. Int $\mathrm{J}$ Inf Technol. https://doi.org/10.1007/s41870-019-00360-4

17. El-Gazzar R, Hustad E, Olsen DH (2016) Understanding cloud computing adoption issues: a Delphi study approach. J Syst Softw 118:64-84

18. Alkhlewi A, Walters R, Wills G (2015) Factors influencing the implementation of a private government cloud in Saudi Arabia. In: Proceedings of the 2nd international workshop on emerging software as a service and analytics. SCITEPRESSScience and Technology Publications, pp 69-72. https://doi. org/10.5220/0005528000690072

19. Alfarraj O, Drew S, AlGhamdi R (2012) EGovernment stage model: evaluating the rate of web development progress of government websites in Saudi Arabia. Int J Adv Comput Sci Appl 2(9):82-90

20. Alshehri M, Drew S, AlGhamdi R (2013) Analysis of citizens acceptance for e-government services: applying the UTAUT model. arXiv preprint arXiv:1304.3157

21. Odeh M, Garcia-Perez A, Warwick K (2017) Cloud computing adoption at higher education institutions in developing countries: a qualitative investigation of main enablers and barriers. Int J Inf Educ Technol 7(12):921-927

22. Karim F, Rampersad G (2017) Cloud computing in education in developing countries. Comput Inf Sci 10(2):87-96

23. Alharthi A, Alassafi MO, Walters RJ, Wills GB (2017) An exploratory study for investigating the critical success factors for cloud migration in the Saudi Arabian higher education context. Telematics Inform 34(2):664-678

24. Kauffman RJ, Ma D, Yu M (2014) A metrics suite for firmlevel cloud computing adoption readiness. In: International conference on grid economics and business models. Springer, Cham, pp 19-35

25. Alonso J, Escalante M, Orue-Echevarria L (2016) Transformational cloud government (TCG): transforming public administrations with a cloud of public services. In: Cloud forward, pp 43-52

26. Surya GSF, Surendro K (2014) E-readiness framework for cloud computing adoption in higher education. In: 2014 International conference of advanced informatics: concept, theory and application (ICAICTA). IEEE, pp 278-282

27. Corradini F, De Angelis F, Polini A, Sabbatini S (2015) Cloud readiness assessment of legacy application. In CLOSER, pp 119-126

28. Brandis K, Dzombeta S, Colomo-Palacios R, Stantchev V (2019) Governance, risk, and compliance in cloud scenarios. Appl Sci $9(2): 320$

29. IDC (2017) IDC predicts Saudi ICT market to Bounce Back in 2017 , with NTP initiatives spurring spending to $\$ 33.8 \mathrm{Bil}-$ lione. Retrieved 4 June 2020, from http://www.idc.com/getdo c.jsp?containerld=prCEMA42254117\&pageType=PRINTFRIEN DLY

30. Alsanea M (2016) The adoption of cloud computing, challenges, and solutions. Doctoral dissertation, Goldsmiths, University of London

31. CITC-Communication and Information Technology Commission (2019) Cloud computing regulatory framework. Retrieved 30 May 2020, from https://www.citc.gov.sa/en/RulesandSy stems/RegulatoryDocuments/Documents/CCRF_En.pdf

32. Zabadi AM, Al-Alawi AH (2016) University students' attitudes towards e-learning: University of Business \& Technology (UBT)-Saudi Arabia-Jeddah: a case study. Int J Bus Manag 11(6):286-295

33. Sugawara E, Nikaido $H$ (2014) Properties of AdeABC and AdelJK efflux systems of Acinetobacter baumannii compared with those of the AcrAB-TolC system of Escherichia coli. Antimicrob Agents Chemother 58(12):7250-7257. https://doi. org/10.1128/AAC.03728-14

34. Mansour IEA, Cooper K, Bouchachia H (2016) Effective live cloud migration. In: 2016 IEEE 4th international conference on future internet of things and cloud (FiCloud). IEEE, pp 334-339

35. Alrashed MA, Alotaibi MB (2017) The role of trust in the acceptance of government cloud: an empirical study. IJTD 8(3):1-19

36. Alamri BH, Qureshi MRJ (2015) Usability of cloud computing to improve higher education. IJ Inf Technol Comput Sci 9:59-65

37. Benbasat I, Goldstein D, Mead M (1987) The case research strategy in studies of information systems. MIS Q 11(3):369386. https://doi.org/10.2307/248684

38. Kitchenham B, Pickard L, Pfleeger SL (1995) Case studies for method and tool evaluation. In: IEEE software

39. Kitchenham BA, Pfleeger SL, Pickard LM, Jones PW, Hoaglin DC, El Emam K, Rosenberg J (2002) Preliminary guidelines for empirical research in software engineering. IEEE Trans Softw Eng 28(8):721-734

40. Andersson C, Runeson P (2007) A replicated quantitative analysis of fault distributions in complex software systems. IEEE Trans Softw Eng 33(5):273-286

41. Runeson P, Höst M (2009) Guidelines for conducting and reporting case study research in software engineering. Empir Softw Eng 14(2):131

42. Bhattacherjee $A$ (2001) Understanding information systems continuance: an expectation-confirmation model. MIS Q $25: 351-370$

43. ISACA (2011) COBIT process assessment model (PAM): using COBIT 4. 1., ISACA

44. Bourque L, Fielder EP (2003) How to conduct self-administered and mail surveys, vol 3. Sage, Thousand Oaks 
45. Kitzinger J (1995) Qualitative research; introducing focus groups. BMJ 311:299-302

46. Morgan DL (1996) Focus groups as qualitative research, vol 16. Sage, Thousand Oaks

47. McLafferty I (2004) Focus group interviews as a data collecting strategy. J Adv Nurs 48(2):187-194
48. Cronbach LJ (1951) Coefficient alpha and the internal structure of tests. Psychometrika 16(3):297-334

Publisher's Note Springer Nature remains neutral with regard to jurisdictional claims in published maps and institutional affiliations. 